\title{
Modeling the Crowdsourcing Effective Factors on Marketing in Tourism Industry
}

\author{
Rouhollah Tavallaee ${ }^{1}$, Nasim Hosseinzadeh Nosrati ${ }^{2,}$, , Mohammadreza Hosseini ${ }^{3}$, \\ Bahar Hosseinzadeh Nosrati ${ }^{4}$ \\ ${ }^{1}$ Management Department, Shahid Beheshti University, Tehran, Iran \\ ${ }^{2}$ Management \& Accounting Department, Seraj University, Tabriz, Iran \\ ${ }^{3}$ Management Department, Central Branch, Islamic Azad University, Tehran, Iran \\ ${ }^{4}$ Management Department, University College of Nabi Akram, Tabriz, Iran
}

\section{Email address:}

tavallaee.r@gmail.com (R. Tavallaee), Nasim2hosseinzadeh@gmail.com (N. H. Nosrati), Mr.hosseini.fc@gmail.com (M. Hosseini), b.hosseinzadeh93@gmail.com (B. H. Nosrati)

*Corresponding author

\section{To cite this article:}

Rouhollah Tavallaee, Nasim Hosseinzadeh Nosrati, Mohammadreza Hosseini, Bahar Hosseinzadeh Nosrati. Modeling the Crowdsourcing Effective Factors on Marketing in Tourism Industry. American Journal of Operations Management and Information Systems.

Vol. 5, No. 1, 2020, pp. 1-12. doi: 10.11648/j.ajomis.20200501.11

Received: December 1, 2019; Accepted: February 12, 2020; Published: February 25, 2020

\begin{abstract}
Current era is customer-orientation era and organizations try hard to satisfy their customers and do their best in marketing. There are numerous factors affect customer satisfaction. One of these important factors is crowdsourcing. Crowdsourcing is one of the emerging Web based phenomenon which has attracted great attention from both customers and researchers over the years. Therefore, to investigate it and its effective factors is needed. So, this research is modeling the crowdsourcing effective factors on marketing in tourism industry. Current research is applied one and seeks to identify crowdsourcing effective factors on customer satisfaction in tourism industry. Also, research method is descriptive-survey. So, the independent and dependent variables have been introduced at the first part by literature review. Then, the identified factors in the model has been validated by using judgmental method and 7 experts' viewpoints in tourism field. To present the final conceptual model, fuzzy cognitive mapping and expert mind map drawing have been used. Findings have indicated that among the technology factor indexes, the "social networks" index had the most effect; among environmental factor indexes, the "applying competitive competitiveness" index had the most effect; among the product market price factor indexes, the "consumer price elasticity" index had the most effect; among the executive decisions factor indexes, the "high income for better planning" index had the most effect; among the financial flows factor indexes, the "organizing suitable individual" index had the most effect; among the motive forces factor indexes, the "task attractiveness" index had the most effect; among the main factors indexes, the "using the newest sources" index had the most effect and among task features indexes, the "creativity in performing the task" index had the most effect. Also, recommendations have been presented.
\end{abstract}

Keywords: Information \& Communication Technology, Crowdsourcing, Marketing, Tourism Industry, Fuzzy Cognitive Mapping

\section{Introduction}

Customer satisfaction and marketing have turned to main concerns of the organizations. Current era is customerorientation era and organizations try hard to satisfy their customers and do their best in marketing. There are numerous factors affect customer satisfaction. One of the main factors which has been considered less by Iranian organizations \& their managers is "crowdsourcing" phenomena. This phenomenon is of the modern techniques in business \& others fields. Crowdsourcing is one of the emerging Web based phenomenon which has attracted great attention from both customers and researchers over the years. This phenomenon can facilitate the connectivity and 
collaboration among people, organizations, and societies as well as can affect the customer satisfaction through this. [43]. The widespread application of this phenomena has been seen and is considerable by most of the researchers, yet. Crowdsourcing gives main roles to individuals \& groups through which the organizations can assign their tasks to them. Crowdsourcing which is defined as follow; "the process of achieving the needed service, idea \& content by getting help from a large group of online people" is used increasingly in marketing. Crowdsourcing seeks to mobilize the capabilities \& skills which are spread out among the individuals and existed in different types. Actually, crowdsourcing is a force-based model in which the organizations use the advanced internet technologies temporarily to apply the attempts of virtual crowd to perform the specific organizational tasks. [32].

Today, crowdsourcing has entered to tourism sector and is used more in this sector. Thus, considering it and its effective factors in marketing is necessary. So, this research seeks to present a model for crowdsourcing effective factors on marketing in tourism sector.

\section{Literature Review}

Crowdsourcing

This phenomenon was defined for the first time by [20] in Wired Magazine. It was defined as "the act of a company or institution taking a function once performed by employees and outsourcing it to an undefined (and generally large) network of people in the form of an open call". [20] Crowdsourcing has academic base as well as has a start-up. It gives us complete $\&$ comprehensive information. It forces us toward problem solving skills.

Crowdsourcing is an action or a practice which is considered by a firm or an entity. It is a conducted performance by the employees or a network of online crow. The crowdsourcing functional \& strategic plans have been whispered during recent years and have been included idea generation, small organizing for the operation, open source software and public participation as well as urban knowledge, urban journalism and Wikis. [7]. Also, it is defined as the action uses a group of people to decide, innovate \& solve problems. [20].

The nature of crowdsourcing is the general mobilization of creative ideas by the consumers. [33].

Howe (2006), (2011) offers the two following definitions for crowdsourcing:

a) The White Paper Version: Crowdsourcing is the act of taking a job traditionally performed by a designated representative (usually an employee) and outsourcing it to an undefined, generally large group of people in the form of an open call.

b) The Sound-bite Version: The application of Open Source principles to fields outside of software. (For example; open Street Map). [33].

Alonso \& Lease (2011) have defined crowdsourcing; outsourcing the task to a large group instead of assigning such tasks to the staff. [2].

i. [8]; the individuals are paid to do the web-based tasks. [8].

ii. [6] defines it as "an online problem solving process as well as a production model which is usually used for firm profitability. Also, it is defined as a strategic model which attracts a group of motived \& interested individuals with high problem solving ability [6].

iii. [11] consider it as a specific sample of collective knowledge. [11].

iv. [12] believe that crowdsourcing is a method through which firms can achieve external knowledge. [12].

v. [15] its general aim is problem solving. [15].

vi. [17] consider it as a relative new phenomenon in which staff often perform a task for less payments [17].

vii. [19] believe that it is a commercial open source method makes the most use of people across the social network. [19].

viii. [20] it is a mechanism through which the knowledge $\&$ talent are given to those who need it. [20].

ix. [22] it is the form of users \& consumers' integration in internal value creation processes. [22].

x. [15]; it is outsourcing tasks online to the public. [15].

xi. [23] it is a tool to investigate the problems across an organization or a business. - [23].

xii. [28] consider it as general mobilization through internet creative \& innovative ideas to solve a problem. [28].

xiii. [29] it is a method to outsource tasks to the public for creating spiritual properties commonly with the aim of ease accessibility to a widespread type of skills \& experiences. [29].

xiv. [41] the process of outsourcing activities to an online society in the form of a call by a firm. [41].

Crowdsourcing types

[6], has described four types of crowdsourcing;

a) Knowledge discovery \& management approach: to employ the crowd with funding as well as to organize existing widespread knowledge.

b) The broadcast search approach: often is used to assign task to the crowd with the problem solving ability often scientific.

c) The peer-vetted creative production approach: assigning a task with the aim of creating \& storing the ideas.

d) Distributed human intelligence task assignment: to assign widespread data. [6]

Crowdsourcing applications

As it has been described in various researches, crowdsourcing has three application;

a) Involving the consumer in the company communication: crowdsourcing to organizations, customers \& site users by all of the organizations \& firms to improve their goods and services. So that the customers \& users are asked to give their advices on a good or service. Then, their advices are being investigated and revised as well as the best ones which 
can affect good or service quality are selected. For instances, Dell has had a website in which it asks its customers to give their views and experiences on the firm's products. Then the ideas are investigated and the best one is selected as well as the winner is rewarded.

b) Alternative to costly communication professionals: crowdsourcing to researchers and scholars of a specific scope. So that, an institution calls up the scholars \& researchers of a specific scope when it has a research plan or a problem.

c) Commercial crowdsourcing or advertising: crowdsourcing to the public not staff. The organization introduces a series of products which are going to be presented by it. The crowd is asked to present the products they can produce. Then, the provided products are investigated and reviewed by the organization experts as well as the best ones are selected and presented on the organizations. Examples are Faradars and other similar organization in Iran. Some needed courses are introduced on the site and the crowd are asked to produce each of them, they can. Then, the organization selects the best ones and presents them on the site. It asks its customers to produce the T-shirt, mugs and banners with the firm's logo. Then, the best ones are present on the site for selling. [14].

Crowdsourcing and outsourcing differences

According to [20] crowdsourcing has been investigated from the outsourcing viewpoint for the first time.

[43] believe that outsourcing can be in the form of purchasing a good or service in its easiest form which has been presented by the internal producers. [43].

Also, it is defined as contracting for internal different tasks or needs for external service providers. [14].

Despite crowdsourcing is the integrated form of outsourcing, crowdsourcing \& outsourcing have common aims in which external sources are used to satisfy internal needs.

As it is understood, outsourcing is assigning some part of affairs to an expert group from a specific organization. In outsourcing a group or individuals who have specific abilities $\&$ talents are hired from other organizations as well as are tasking. But, the people such as customers or site users are employed from out of the organization in crowdsourcing.

Table 1 describes the differences between crowdsourcing \& outsourcing;

Table 1. The differences between crowdsourcing \& outsourcing.

\begin{tabular}{ll}
\hline Crowdsourcing & Outsourcing \\
\hline All can participate & Only definite people can participate \\
Problems are publicizing & The problem is only defined \\
The best idea gets the reward & According to contract \\
No assurance for the solutions & Trust is high due to the experts \\
High risk due to knowledge & Agent reputation \& expert make the \\
sharing & relation \\
High cost risk & low cost risk \\
Product improvement & Competitive advantage creation \\
\hline
\end{tabular}

[27].
Crowdsourcing in tourism industry

Since crowdsourcing is new in tourism, there are less projects on its effects \& application in tourism. A series of crowdsourcing theories and applications have been presented as follow;

i. [24] have updated the tourism knowledge and information by the tourists helps.

ii. Some sites as Karvaval and Mapgard are working in tourism field as well as apply both mentioned types of crowdsourcing for customer satisfaction and product improvement.

So that some writers are employed from the outside of the organization. They work round and part time. Several subjects are determined and writers are asked to write about that subjects in less payment. Also, they asks their customers and fans to share their videos, images and logbooks. These will result in innovation \& customer loyalty through creating a good and valuable sense in them.

Open Street Map, Wikivoyage are kind of sites in which the maps \& other related information to tourism are designed $\&$ gathered by volunteers who collect $\&$ share their tourism interests \& experiences.

The Personalized Travel System based on Crowdsourcing by [44] and Tag Tag City are examples of tourism Web applications supported by Crowdsourcing.

Kamino is a location-based mobile application which offers crowd-sourced city guides, including attractions, restaurants, shops and other relevant complimentary information, while the user is walking around the city.

Stereo public is a mobile crowdsourcing application which gathers and shares data regarding quiet public spaces.

The Holiday Check travel platform, which works with several well-known tour operators, relies on the crowd to rate hotels, share photos, videos and travel experiences. Rating, sharing and posting correspond to the type of user feedback and crowd-sourced data we are considering.

Crowdsourcing in Marketing

According to the expansion of marketing activities in tourism, internet application became more as well as made everything available. Tourism organizations can use this tool to increase customer loyalty as well as make available their needed goods \& services. But, to do that the human resource advantage should be used online. Sites and organizations can apply interested loyal users.

[26] believes that crowdsourcing can affect marketing since the crowd is the representative of people and his/her viewpoint can represent customers' demands, ideas and wants. We can achieve customer loyalty \& satisfaction by satisfying these needs. [26].

Crowdsourcing is a way to introduce new products by the firm which may result in the strongest brand image. In crowdsourcing application part, it has been pointed that the organizations asks idea from their customers. Indeed, this action will create a good sense in customer. This will cause to customer loyalty at the end. Some examples are Dell \& Alibaba sites. They detect their products' weakness through this way and improve them. 
Also, My Starbucks asks its customer to share their ideas and experiences so that has better relations with the customers as well as improves their goods \& services.

i. Converse Shoes firm accepts home advertisements in "Converse Gallery" site. [10].

ii. Chevrolet, also has applied crowdsourcing in its form and has let its customers to put a 30 second video on their experience with their 'Chevrolet'.

iii.Dell has held a match among the students of Austin University in Texas and asked them to design new \& odd projects to answer customers' new needs. The reward was 50000 dollars. Finally, the best projects have been selected for better servicing to customers.

iv. General Mill seeks ideas on packaging and new product field by the crowd to improve servicing.

Other known examples in crowdsourcing

i. My Starbucks Idea: Submit ideas for Starbucks products

ii. Idea Brewery: review brands \& business ideas.

iii. Unilever: open innovation for social goods. iv. Start Some Good: Crowd funding for social goods.

v. Facebook Translation: employing wisdom of crowds is offering the advantage of providing site versions that are more compatible with local cultures. [18].

vi. Minted Product design: crowd-sources design from independent artists and sells the designs as "fine products such as stationery, wall art, and décor for the home, holidays, and occasions. Minted was an early pioneer of crowdsourcing product design and has held open art and graphic design challenges monthly since 2008".

vii. Click advisor Consumer research: Click advisor provides a range of crowdsourcing based research services by using "consumers as brand advisors who review products, decisions and concepts and offer advice on how they can be improved".

viii. Idea Bounty Creative ideas and marketing solutions. Idea Bounty offers a crowdsourcing platform for companies to crowd source creative ideas and marketing solution to over 200000 registered creative idea generators, who are ready to take on challenging client briefs.

Table 2. Crowdsourcing in marketing activities.

\begin{tabular}{ll}
\hline Marketing Activity & Crowdsourcing Application \\
\hline Product management & Widely accepted crowdsourcing is used to support new ideas and new products development as well as testing of prototypes. \\
Distribution management & $\begin{array}{l}\text { Crowdsourcing especially might be successful in information product distribution, but also crowd labor might be applied for } \\
\text { distribution tasks in physical market. }\end{array}$ \\
Communication & Often addressed issue in research as Internet mainly serves as communication channel. Companies can allocate different \\
management & communication tasks to users through crowdsourcing. \\
Marketing research & Crowdsourcing enables to get feedback and opinion from the crowd, however engagement and quality assurance issues are \\
critical
\end{tabular}

[16]

\section{Research Background}

Tiwari \& Kaushik (2014), (2015) have presented a mobile location-aware tourism recommendation system enriched by Crowdsourcing. Vohnout et al. (2014) have presented Smart Tourist Data, a proposal for the integration of open linked tourism data sources. In this case, the Crowd-sourced data is provided by Linked Open Data (LOD) repositories such as Open Street Map, Open Weather Map or Wiki travel. [3] have proposed Crowdsourcing as a means to generate the initial data set for a personalized tourist attraction recommendation system. [1] have investigated the use of Facebook as governmental media for getting tourism experiences from tourists to improve tourism industry. They have presented; can crowdsourcing be used for crowdsourcing travel information \& experiences for government tourism institutions? This case study has presented both qualitative \& quantitative analysis of FB page of Tourism Australia \& provided an in depth understanding of citizen participation \& contribution in the FB page. Their findings have indicated that the page has served successfully as a platform for its audience by getting both Australians \& tourists from all over the world to suggest locations, uploaded photos, answers, questions \& give advices. [24] have provided a recommendation of tourism resources program by crowdsourcing. To do this, trust \& reputation for the validation of uploaded resources as well as publishers, big Data for users profiling \& context-aware filtering algorithm for the personalized recommendation of tourism resources. This research has been conducted through related surveys to tourism. The results have anticipated recommendations to tourists. [34] have presented a model of effective factors on crowdsourcing. In their model; factors such as the quantity \& quality of the tasks, market competition and so on have been investigated. Their results have indicated that higher awards easier tasks, longer duration \& lower competition intensity lead to better crowdsourcing. Also, higher award, longer duration \& higher difficulty level of task lead to higher ability of sources. [4] believe that crowdsourcing is the use of crowd to create new products \& improve consumer experiences. When it is used in brand \& marketing scope, it will engage consumers by asking them to be part of a branding system \& their experience will be used in decisions. Also, crowdsourcing provides good marketing opportunities for firms. [16] have investigated crowdsourcing application in marketing. Factors affecting consuners involvment in crowdsourcing activities have been investigated as well as the role of crowdsourcing in firms marketing activities has been investigated. From the marketing perspective crowdsourcing can be used in various 
activities such as market research, communication, new products development, etc. Digout et al. (2013) have investigated how crowdsourcing directly affect the variables of the marketing mix such as product development, price positioning, distribution \& communication. Also, it affects people, process \& physical evidence.

\section{Research Methodology}

\subsection{Research Method}

Current research is applied one and seeks to identify crowdsourcing effective factors on marketing in tourism industry. Also, research method is descriptive-survey. So, the independent and dependent variables have been introduced at the first part by literature review. Then, the identified factors in the model has been validated by using judgmental method and 7 experts' viewpoints in tourism field. To present the final conceptual model, fuzzy cognitive mapping and expert mind map drawing have been used.

Cognitive mapping contains two basic elements namely concepts and causal relations. Concepts are reflected in "variables" while causal relations are shown by variables' interrelations. Causal relations connect the variables to each other and can be either positive or negative. The variables resulting in changes are called "cause" variables; whereas those affected by the changes are called "effect" variables [24]. If there is a direct (positive) relation between two variables; then an increase or decrease in the cause variable is accompanied with similar change in the same direction in "effect" variable. If there is an inverse (negative) relation, the change imposed to "cause" variable is also observed in the "effect" variable in opposite direction. [4]

Considering qualitative nature of cognitive mapping and quantification capacity of fuzzy theory, Kosko introduced the concept of fuzzy cognitive map (FCM) in 1986. In contrast to common cognitive maps, fuzzy cognitive map assigns a number, instead of 0 , to each element that shows the strength of the causal relation.

Development of a FCM requires inputs resulting from experts' experience and knowledge. Thus accumulated experience of the experts is integrated with the available knowledge that forms the basis for drawing cause-effect relations among the system components [16].

FCMs represent fuzzified cognitive maps that enables to assign values between -1 and 1 to causal relations; the weight (w) attributed to a one-way arch from node $\mathrm{x} 1$ to node $\mathrm{x} 2$ is expressed quantitatively; showing that to what extent the concept X1 causes the concept $\mathrm{x} 2$. Thus, FCMs are more inclusive than common cognitive maps.

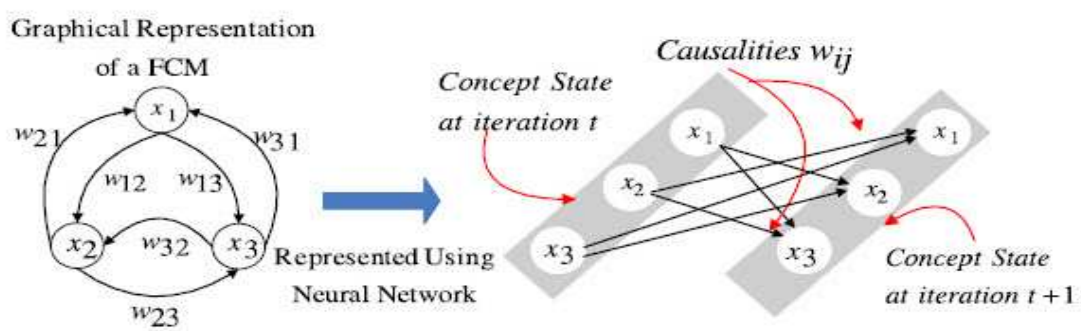

Figure 1. The steps of drawing a FCM [14].

An example of FCM is represented in this figure. Variables $\mathrm{C}_{1}, \mathrm{C}_{2}, \mathrm{C}_{3}, \mathrm{C}_{4}, \mathrm{C}_{5}$ are drawn as nodes and the causal relations

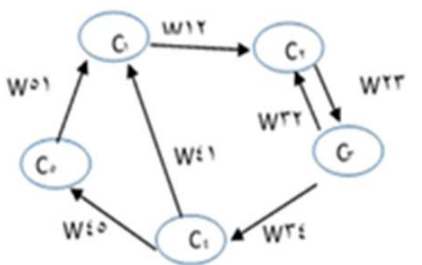

are shoed by the arrows. The magnitude of $C_{i}$ effect on $C_{j}$ is denoted by $\mathrm{W}_{\mathrm{ij}}$ which is a positive or negative value.

$$
\left[\begin{array}{ccccc}
0 & w_{12} & 0 & 0 & 0 \\
0 & 0 & w_{23} & 0 & 0 \\
0 & w_{41} & 0 & w_{34} & 0 \\
w_{34} & 0 & 0 & 0 & w_{45} \\
w_{51} & 0 & 0 & 0 & 0
\end{array}\right]=
$$

Figure 2. An example of FCM and the related matrix.

\subsection{Research Model}

Some researchers $([34,24,39,1,36,37,4,14,31,30,21$, 43], 2012; [16]) have investigated numerous factors and indexes which have been presented in this research as well as have stated below;

In this research not only by reviewing the previous researches, but also by forming Focus Group (7 experts in tourism and marketing) the below indexes have been stated to create a base of common knowledge for identifying, clarifying and exact explaining the factors and indexes;

1) Sites of the Firms \& Organizations

2) Governmental Regulations

3) Controls on the Sites

4) Customer Segmentations by Service

5) Customer Segmentations by Loyalty

6) Main partners' involvement in decision making on the tasks

7) Survey from the partners on the tasks

8) Applying competitive advantage 
9) Organization competitiveness

10) survey from the public on the price

11) customer Price Elasticity

12) Organization high income for better planning

13)Employing valuable experts for related processes

14)Expenses for human resource training

15) Low cost of crowdsourcing

16) Tasks clearness

17) the feedback system appropriateness

18)Organizing suitable individuals

19)Proper control
20)The Task appropriateness

21) The Reward timeliness

22)The Task attractiveness

23)Allocating reward for the task

24)Optimum use of the sources

25)Using the newest sources

26) Task difficulty

27) Appropriate to individual talent

28)Creativity in performing the task

29)Appropriate to individual expert

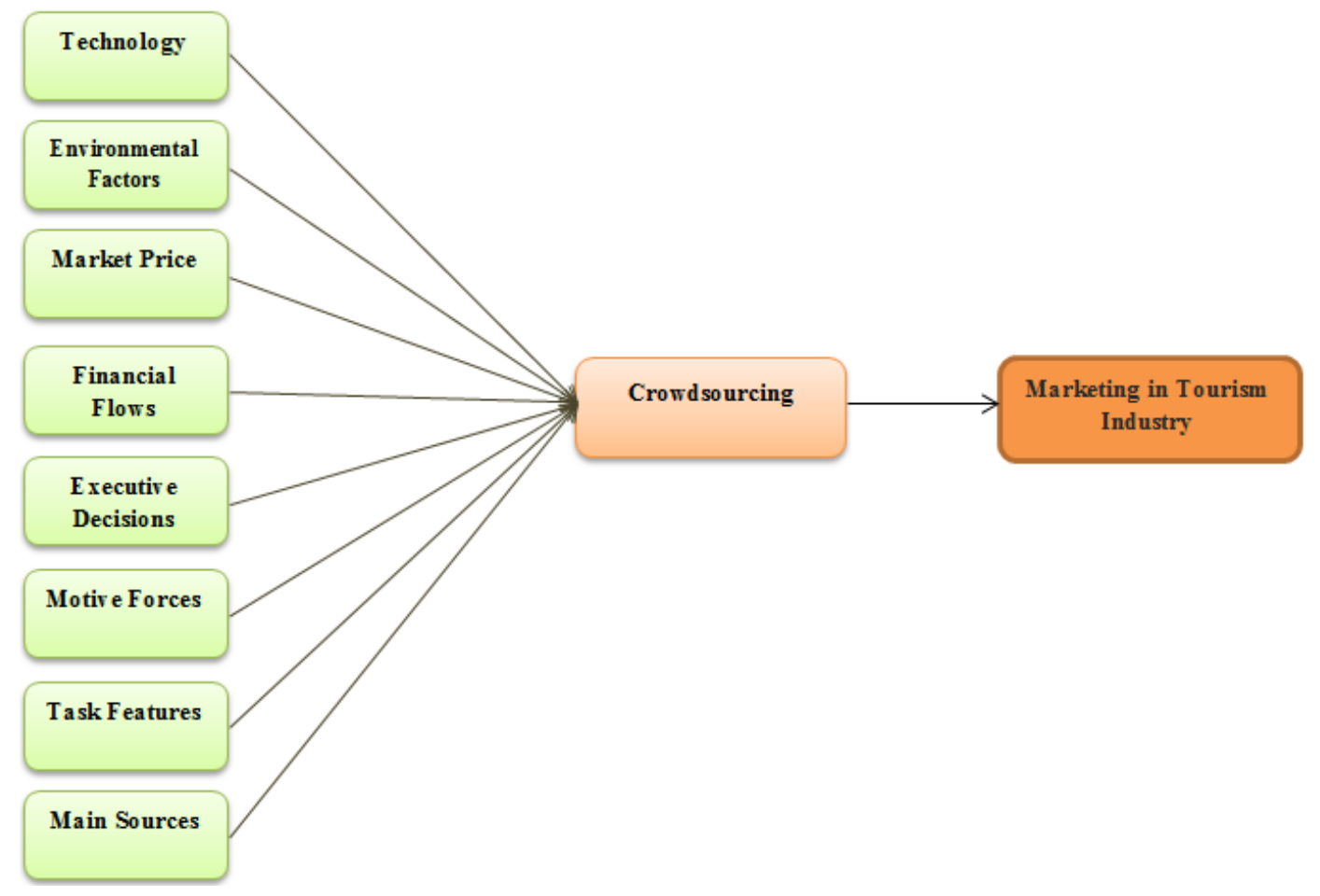

Figure 3. Conceptual model.

\section{Findings}

According to the questionnaire conceptual framework, the effect of some crowdsourcing factors has been investigated on customer satisfaction. Each factor has some indexes. In this part, at first the priority of each index in its related factor has been identified, then the factors have been modeled.

Table 3. Determining the priority of technology indexes.

\begin{tabular}{llll}
\hline Concepts & Outdegree & Indegree & Centrality \\
\hline Social Networks & 138 & 129 & 266 \\
Sites of the firms & 116 & 127 & 243 \\
\hline
\end{tabular}

In the above table, the input, output and centrality degree of each factors have been achieved. The centrality is achieved by the sum of input and output degree. The index with high centrality, has higher priority. So, the "social networks" index was at the first priority with 2.66 centrality value and the "site of firms" index was at the last priority with 2.43 centrality value.
Table 4. Determining the priority of environmental factors indexes.

\begin{tabular}{llll}
\hline Concepts & Outdegree & Indegree & Centrality \\
$\begin{array}{l}\text { Governmental regulations } \\
\text { Control on the sites }\end{array}$ & 4.62 & 3.86 & 8.47 \\
$\begin{array}{l}\text { Customer segmentation by } \\
\text { service }\end{array}$ & 5.36 & 4.62 & 9.12 \\
$\begin{array}{l}\text { Customer segmentation by } \\
\text { loyalty }\end{array}$ & 5.06 & 5.03 & 10.39 \\
$\begin{array}{l}\text { Partners involvement in } \\
\text { decision making }\end{array}$ & 4.58 & 5.27 & 10.33 \\
$\begin{array}{l}\text { Survey from partners on the } \\
\text { tasks }\end{array}$ & 4.90 & 4.63 & 9.22 \\
$\begin{array}{l}\text { Applying Competitive } \\
\text { advantage }\end{array}$ & 5.09 & 4.58 & 9.48 \\
$\begin{array}{l}\text { Organization } \\
\text { Competitiveness }\end{array}$ & 4.76 & 5.58 & 10.68 \\
\hline
\end{tabular}

According to the achieved centrality values; "applying competitive competitiveness" index was at the first priority with 10.68 centrality value and has the most effect as well as the "governmental regulations" index was at the last priority with 8.47 centrality value. 
Table 5. Determining the priority of market price indexes.

\begin{tabular}{llll}
\hline Concepts & Outdegree & Indegree & Centrality \\
\hline Survey on price & 1.38 & 1.40 & 2.78 \\
Customer price elasticity & 1.37 & 1.52 & 2.89 \\
\hline
\end{tabular}

According to table 5; "consumer price elasticity" index was at the first priority with 2.89 centrality value and has the most effect as well as the "survey on the price" index was at the last priority with 2.78 centrality value.

Table 6. Determining the priority of financial flows indexes.

\begin{tabular}{llll}
\hline Concepts & Outdegree & Indegree & Centrality \\
\hline High income for better planning & 2.63 & 2.47 & 5.11 \\
Employing valuable experts & 2.44 & 2.41 & 4.85 \\
$\begin{array}{l}\text { Expenses for human resource } \\
\text { training }\end{array}$ & 2.35 & 2.35 & 4.69 \\
Low cost of Crowdsourcing & 2.27 & 2.46 & 4.37 \\
\hline
\end{tabular}

The centrality of "high income for better planning" index was 5.11 and this index had the most effect. But, "employing valuable experts", "low cost of crowdsourcing" and "expenses for human resource training" indexes were at the next priorities, respectively.

Table 7. Determining the priority of Executive Decisions indexes.

\begin{tabular}{llll}
\hline Concepts & Outdegree & Indegree & Centrality \\
\hline Task dearness & 2.41 & 2.54 & 4.95 \\
The feedback system & 2.49 & 2.60 & 5.09 \\
appropriateness & 2.60 & 2.60 & 5.20 \\
$\begin{array}{l}\text { Organizing suitable individuals } \\
\text { Proper control }\end{array}$ & 2.52 & 2.65 & 5.17 \\
\hline
\end{tabular}

In this factor, the "organizing suitable individual" index had the most priority; so, it has the most effect. After that, the "proper control", "the feedback system appropriateness" and "task clearness" indexes were at the second, third and fourth priorities with 5.17, 5.09 and 4.95 centrality values, respectively.
Table 8. Determining the priority of Motive Forces indexes.

\begin{tabular}{llll}
\hline Concepts & Outdegree & Indegree & Centrality \\
\hline The Task appropriateness & 2.65 & 2.36 & 5.01 \\
The reward timeliness & 2.60 & 2.36 & 4.96 \\
The Task attractiveness & 2.59 & 2.57 & 5.16 \\
Allocating reward for the task & 2.47 & 2.47 & 4.95 \\
\hline
\end{tabular}

According to table 8; the "the task attractiveness" index was at the first priority with 5.11 centrality and "allocating reward for the task "index were at the least priority.

Table 9. Determining the priority of main factors indexes.

\begin{tabular}{llll}
\hline Concepts & Outdegree & Indegree & Centrality \\
\hline Optimum use of the sources & 1.36 & 1.22 & 2.58 \\
Using the newest sources & 1.36 & 1.30 & 2.66 \\
\hline
\end{tabular}

According to centrality values; the "using the newest sources" index was at the first priority and "optimum use of the sources "index was at the least priority.

Table 10. Determining the priority of Task Features indexes.

\begin{tabular}{llll}
\hline Concepts & Outdegree & Indegree & Centrality \\
\hline Task difficulty & 2.49 & 2.09 & 4.58 \\
Appropriate to individual talent & 2.86 & 2.36 & 5.22 \\
Creativity in performing the task & 2.62 & 2.90 & 5.52 \\
Appropriate to individual expert & 2.54 & 2.84 & 5.38 \\
\hline
\end{tabular}

The "creativity in performing the task" index had 5.38 centrality and the most effect. Also, the "appropriate to individual expert", "appropriate to individual talent" and "task difficulty" indexes were at the next priority.

Modeling the factors in crowdsourcing

According to the findings, the mutual effect of crowdsourcing indexes in tourism industry has been achieved. So, if it is closer to one, it will represent the effect intensity better as well as if it is less than 0.5 , it will represent their less effect on each other.

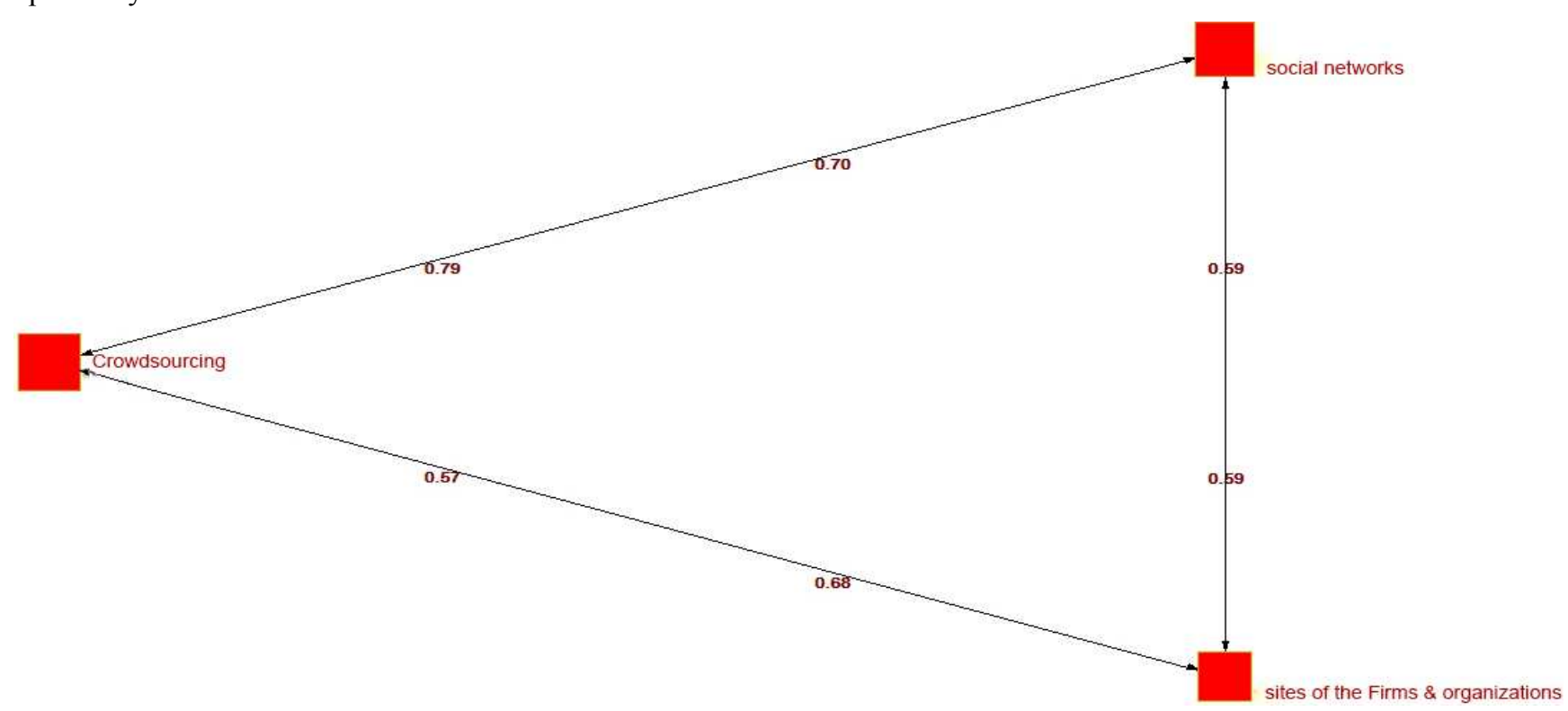

Figure 4. Technology factor modeling. 


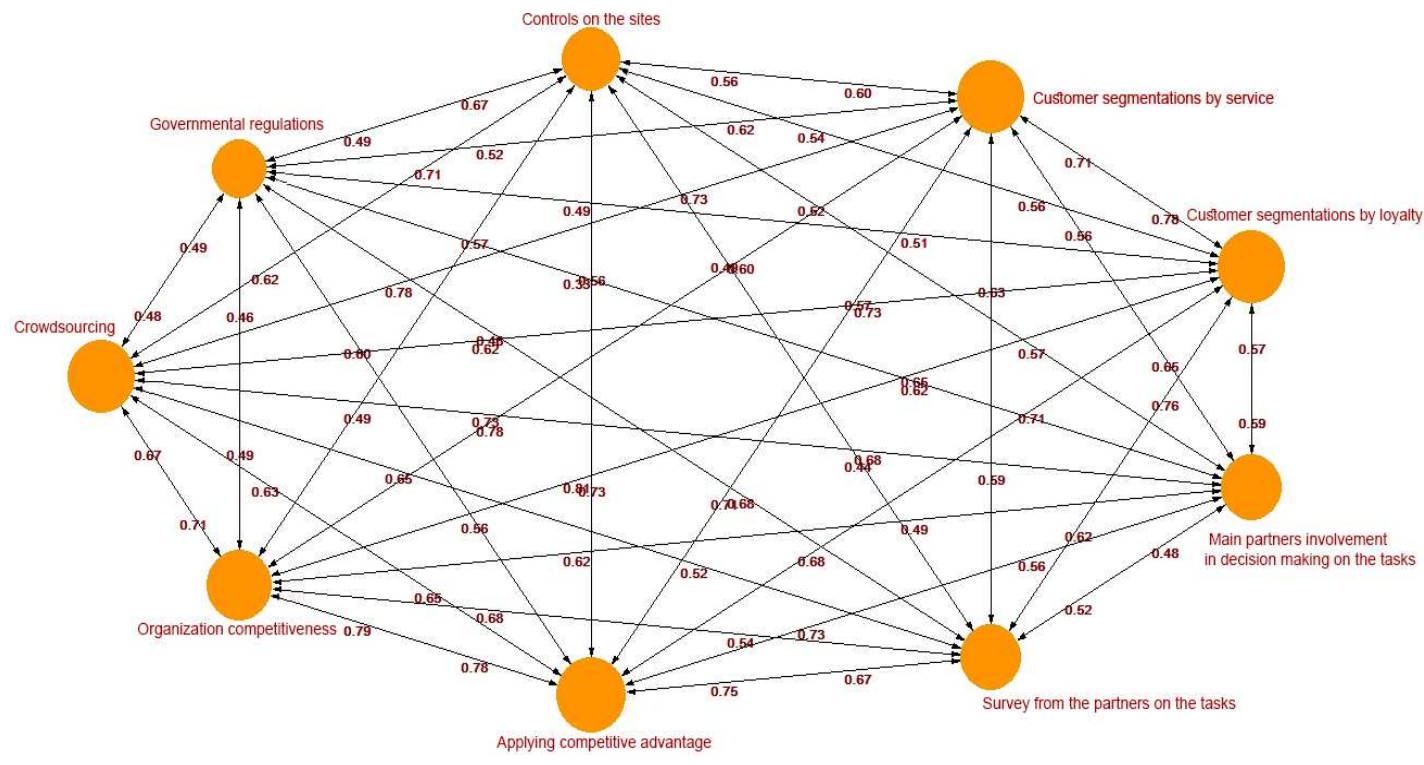

Figure 5. Environmental factors modeling.

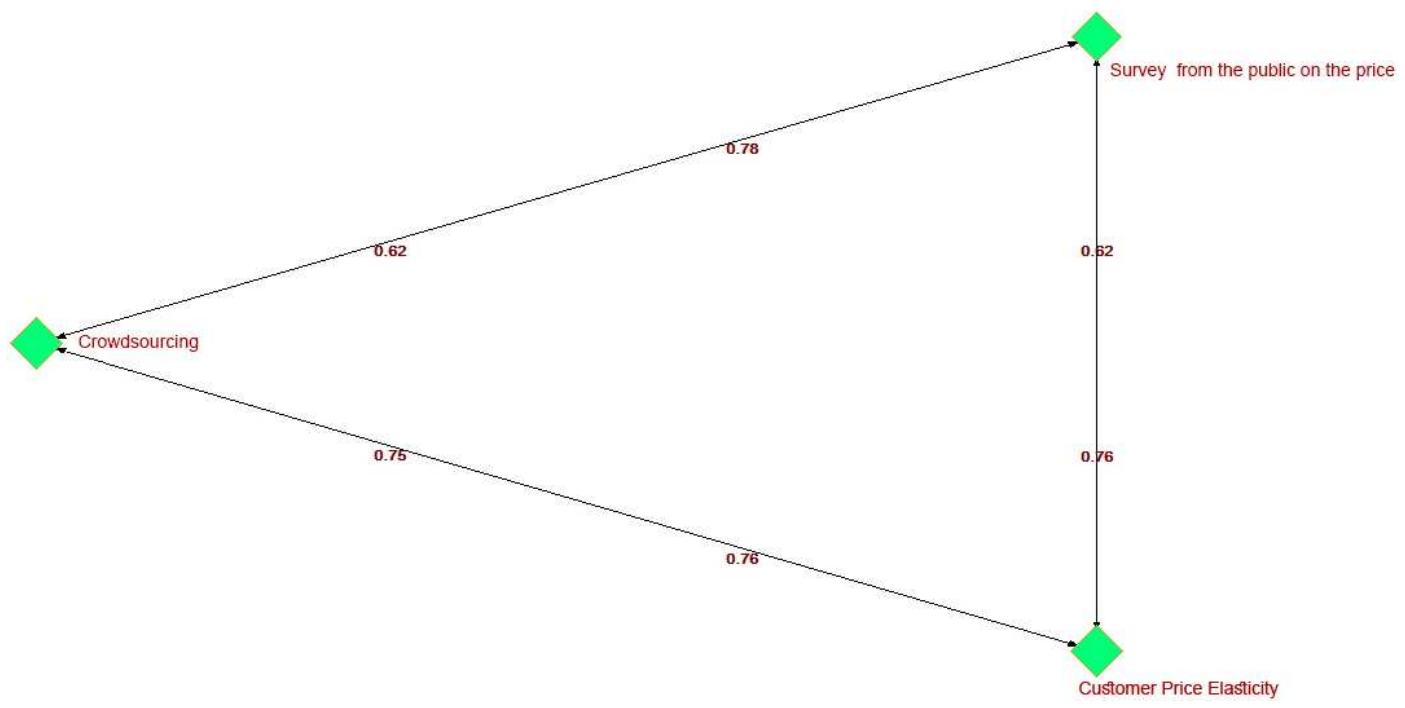

Figure 6. Market price factor modeling.

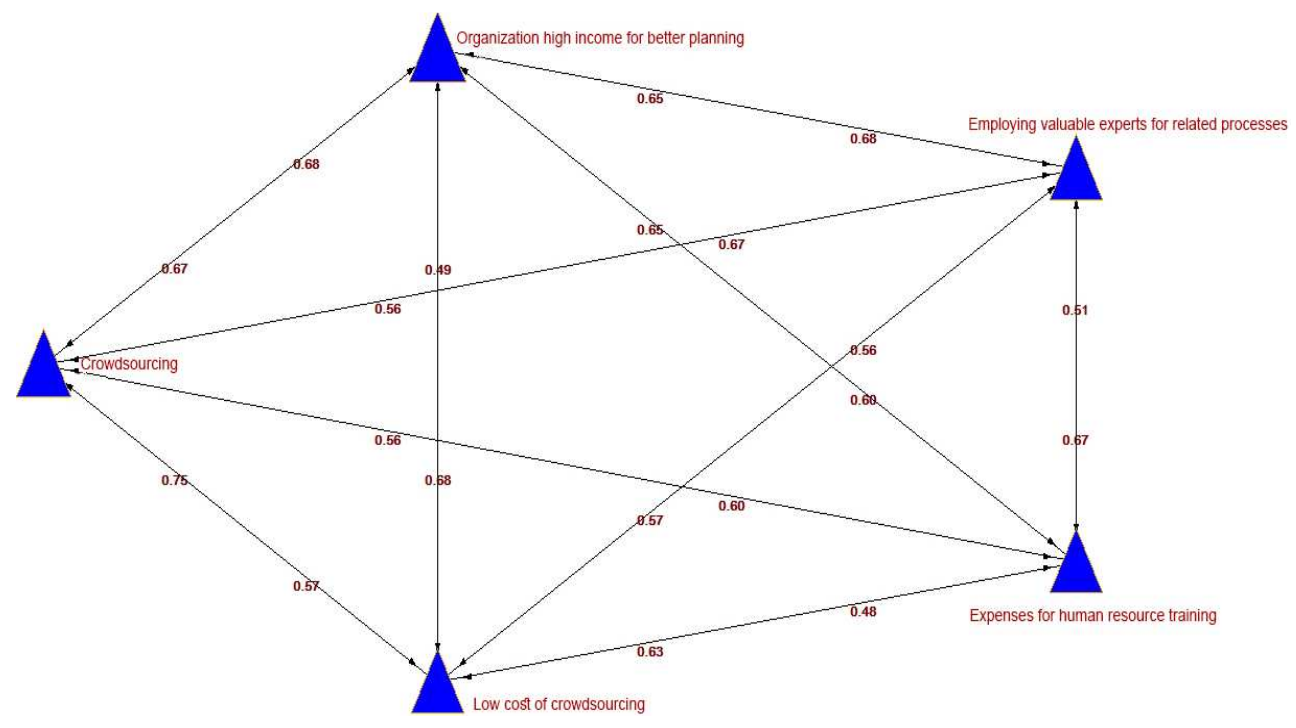

Figure 7. Financial flows factor modeling. 


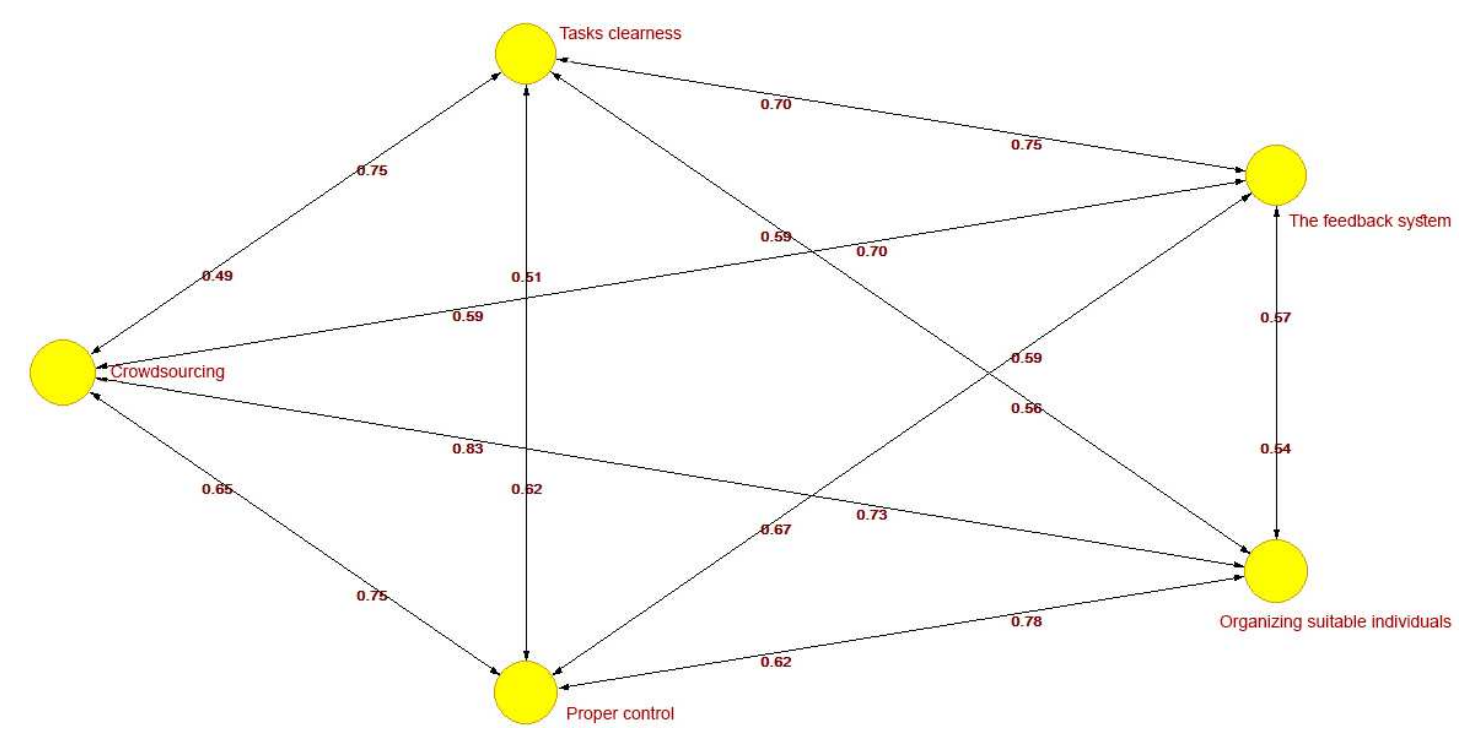

Figure 8. Executive Decisions factor modeling.

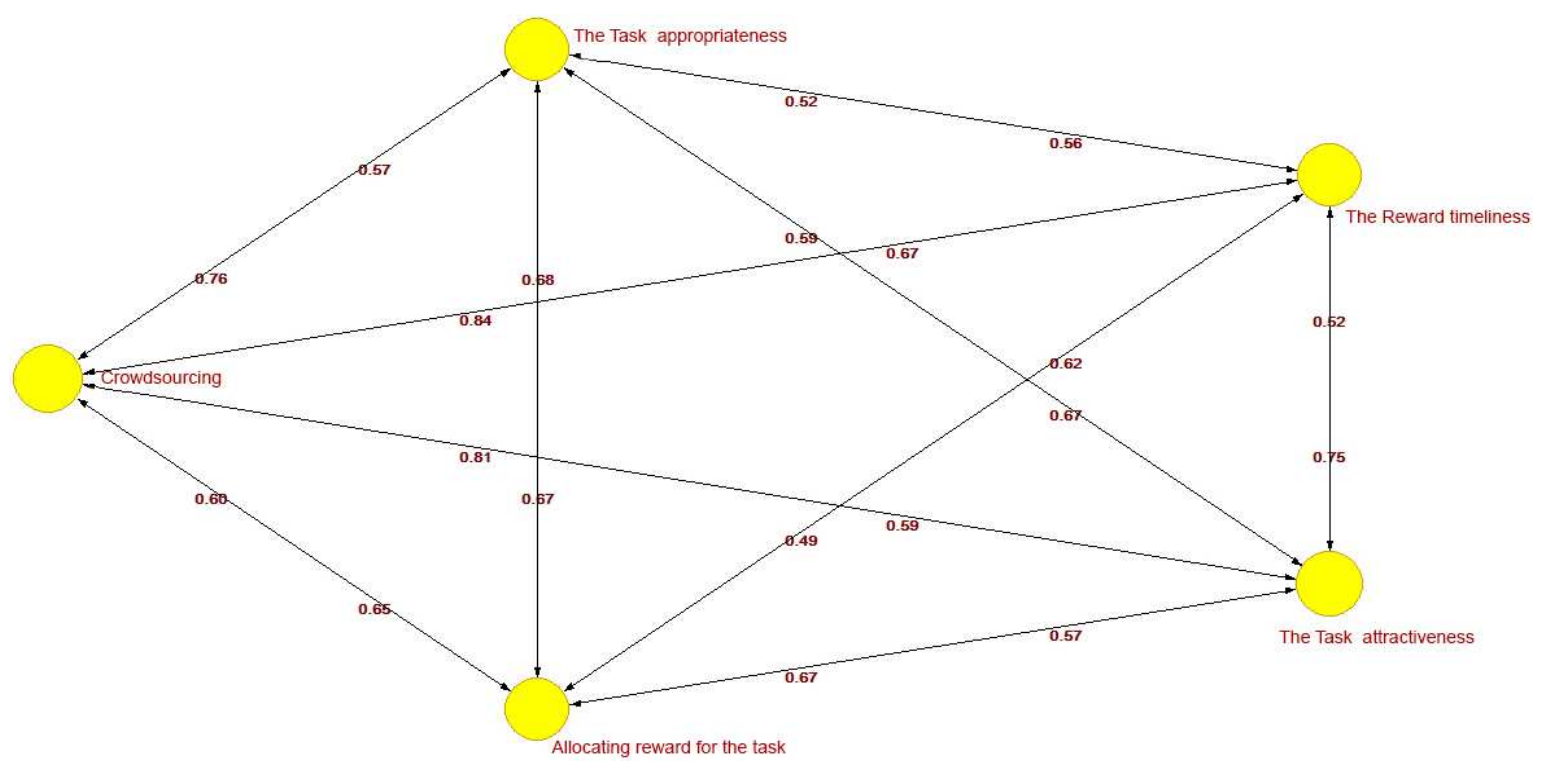

Figure 9. Motive Forces factor modeling.

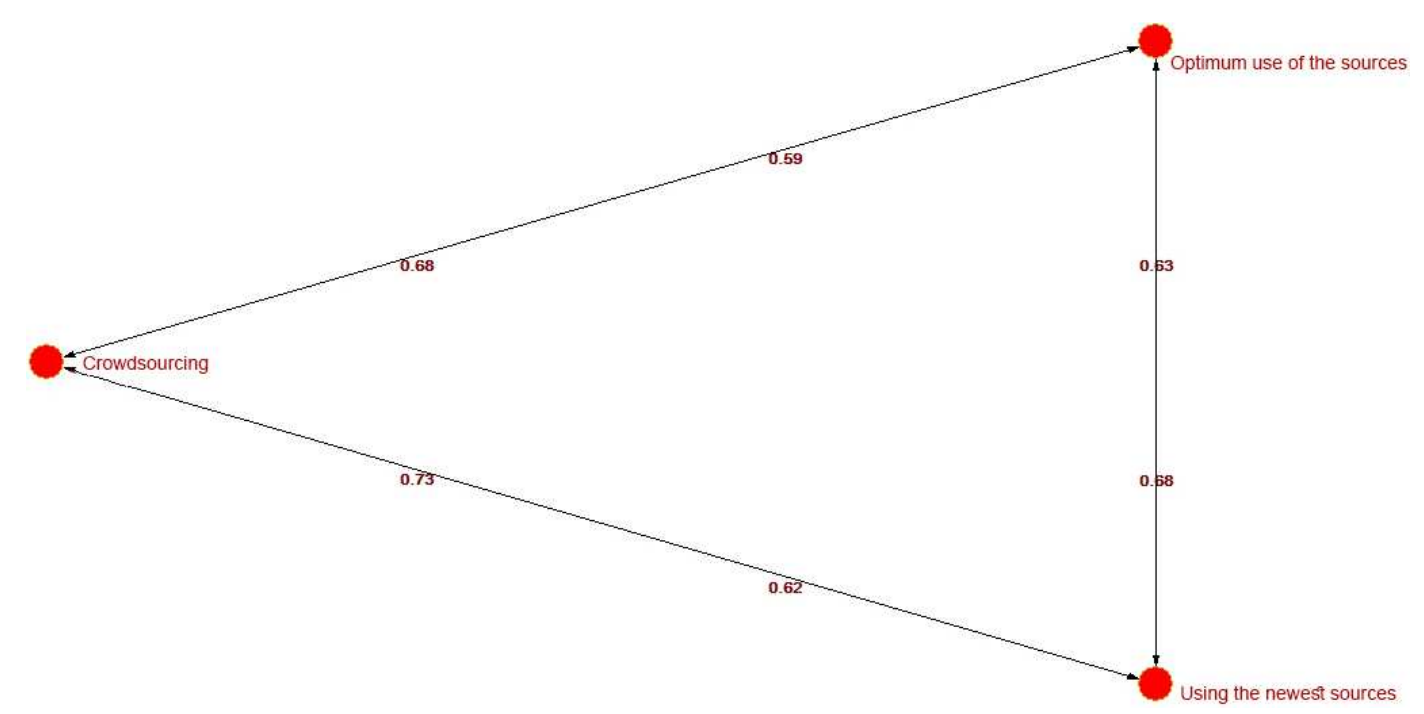

Figure 10. Main Sources factor modeling. 


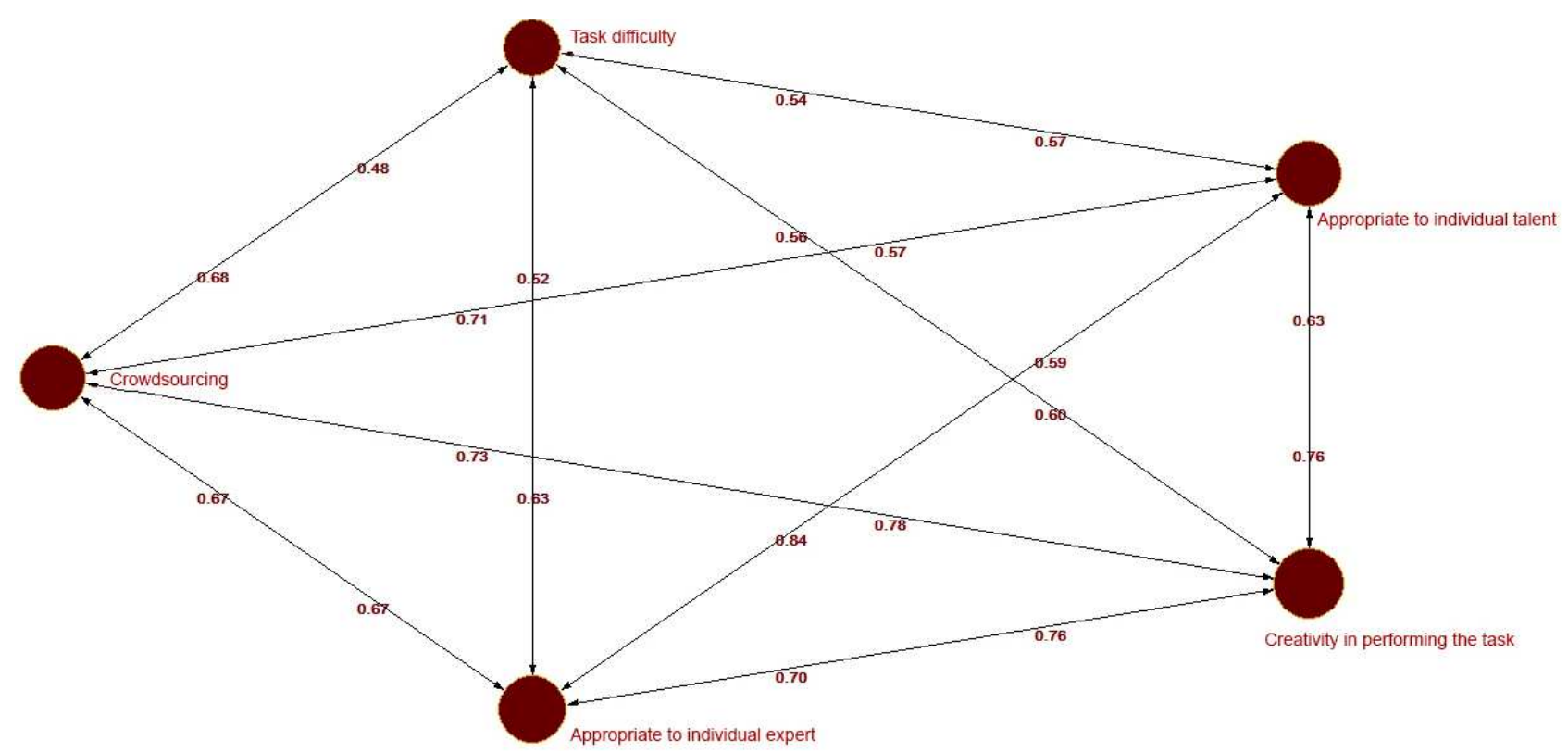

Figure 11. Task Features factor modeling.

\section{Conclusion}

Marketing, especially in tourism has become so widespread these days. Marketing in tourism is very challenging due to the competitive nature of this sector. So, firms must pay more attention to factors which may help them and give competitive advantage to them as well as make them more innovative. One of the new factors which can affect marketing and tourism marketing is crowdsourcing. Crowdsourcing itself is a new concept. It refers to crowd participation in knowledge sharing. It gives decision makers complete \& comprehensive information to decide about main activities in marketing.

Crowdsourcing is an effective tool for improvement of marketing activities including market researches, communication, new product development and trials, development of new ideas, as well as others. When conducted accurately, crowdsourcing plays critical role in content creation process in marketing and involvement of existing and potential tourists in marketing activities of tourism industry.

Some recommendations have been presented based on the indexes with the most effects;

i. According to that the "social networks" index had the most effect in determining the priorities of "technology" factor; it is recommended that the organizations should have new and complete plans to communicate with the individuals and inform them to assign the task better to them.

ii. According to that the "applying competitive competitiveness" index had the most effect in determining the priorities of "environmental factors"; it is recommended that the organizations to identify their competitive advantages better and try to apply them more than before. iii. According to that the "consumer price elasticity" index had the most effect in determining the priorities of "product market price" factor; it is recommended that the organizations to lessen their product costs by assigning some tasks to the talent crowd with low payment.

iv. According to that the "high income for better planning" index had the most effect in determining the priorities of "financial flows" factor; it is recommended that the organizations can achieve more income by more innovations in their products.

v. According to that the "organizing suitable individual" index had the most effect in determining the priorities of "executive decisions" factor; it is recommended that the organizations to have proper planning as well as attract the best and most knowledgeable individuals.

vi. According to that the "the task attractiveness" index had the most effect in determining the priorities of "motive forces" factor; it is recommended that the organizations try to assign the task according to individuals' interest and use them in their favorite field. (Such as Mapgard \& Karnaval which use some in translations and others in writing).

vii. According to that the "using the newest sources" index had the most effect in determining the priorities of "main factors"; it is recommended that organizations to use more updated and more knowledgeable individuals as well as try to update their organizations.

viii. According to that the "creativity in performing the task" index had the most effect in determining the priorities of "task features"; it is recommended that organizations try to attract the most creative ideas and individuals to flow the creativity in their organizations. 


\section{References}

[1] Alam, S. L., MacKrell, D., \& Rizvi, S. U. (2012) Croedsourcing Travel Experience: A case study of user participation on the tourism Australia Facebook Page. Association for Information System.Mediterranean Conference on Information System.

[2] Alonso, O. \& Lease, M. (2011). Crowdsourcing 101: Putting the WSDM of Crowds to Work Work for You. Proceeding of the fourth ACM international conference on Web search and data mining, WSDM.

[3] Bachrach, Y., Ceppi, S., Kash, I. A., Key, P., Radlinski, F., Porat, E.,... Sharma, V. (2014). Building APersonalized Tourist Attraction Recommender System Using Crowdsourcing. Proceedings of the 13th International Conference on Autonomous Agent and Multiagent Systems.

[4] Bal, A. S., Weidner, K., Hanna, R., \& Mills, A. J. (2016). Crowdsourcing and brand control. Business Horizons.

[5] Bayus, B. L. (2010). Crowdsourcing and individual creativity over time: the detrimental effects of past success. SSRN Quantitative Marketing eJournal, Retrieved from http://ssrn.com/abstract01667101.

[6] Brabham, D. C. (2008). Crowdsourcing as a Model for Problem Solving: An Introduction and Cases, Convergence. The International Journal of Research into New Media Technologies, 14 (1), 75-90.

[7] Brabham, D. C. (2008). Moving the crowd at iStockphoto; the composition of the crowd and mitivations for participation in a crowdsourcing application. First Monday, 13 (6).

[8] Bederson, B. B. \& Quinn, A. J. (2011). Web Workers Unite! Addressing Challenge of Online Laborers. Proceedings of Annual conference extended abstracts on Human Factors in Computing Systems.

[9] Brito,, J. (2008). Crowdsourcing government transparency.. The Columbia Science and Technology Law Review, 119-157.

[10] Bosman, J. (2006). Chevy tries a write-your-own ad approach, and the potshots fly. The New York. Retrieved from http://www.nytimes.com/2006/04/04/business/media/04adco.ht $m l ? \_r=0$.

[11] Buecheler, T., Sieg, J. H., Fuchslin, R. M., \& Pfeifer. (2010). Crowdsourcing, Open Innovation and Collective Intelligence in the Scientific Method; A research Agenda and Operational Framework. The International Conference on the Synthesis and Simulation of Living Systems, Odense, Denmark, 679-686.

[12] Burger-Helmchen, T., \& Penin, J. (2010). The limits of crowdsourcing inventive activities; what do transaction cost theory and the evolutionary theories of the firm teach us? Workshop on Open Source Innovation, Strasbourg, France.

[13] Chanal, V., \& Caron-Fasan, M. L. (2008). How to invent a new business model based on crowdsourcing;. The crowdspirit.

[14] Digout, J., Azouri, M., Decaudin, J.-M., \& Rochard, S. (2013) Crowdsourcing to obtain a Creativity Group. The Arab Economic and Business Journal, 8, 6-15.

[15] Donan et al. (2011). Crowdsourcing systems on the WorldWide Web. Communications of the ACM, 54 (4), 86-86.
[16] Gatautis, R., \& Vitkauskaite, E. (2014). Crowdsourcing application in marketing activities. Contemporary Issues in Business, Management and Education, 1243 - 1250.

[17] Heer, J., \& Bostok, M. (2010). Crowdsourcing graphical perception; using mechanical turk to assess visualization design. Proceeding of the 28th international conference on Human factors in computing systems.

[18] Hosaka, T. A. (2008). Facebook asks users to translate for free. 'Crowdsourcing' aids company's aggressive worldwide expansion. NBCNews.com. Retrieved October 21, 2013, from http://www.nbcnews.com/id/24205912.

[19] Howe, J. (2011). Crowdsourcing; A definition. Crowdsourcing: Why the Power of the Crowd is Driving the Future of Business. http://crowdsourcing.typed.com.

[20] Howe, J. (2006). Mission Statement'. Crowdsourcing: Tracking the Rise of the Amateur. URL (accessed 6 May 2007):

http://crowdsourcing.typepad.com/cs/2006/05/hi_my_name_is j.html.

[21] Howe, J. (2006). The rise of crowdsourcing. Wired Magazine, $14(6), 1-4$

[22] Kleeman et al. (2011). Un (der) paid Innovation; The Commercial Uti; ization of Consumer Work through crowdsourcing. Science Technology and Innovation Studies, 53 (12), 5-26.

[23] La Vecchia, G., \& Cisternino, A. (2010). Collaborative workforce, business process crowdsouring as an alternative of BPO. First Interprise crowdsourcing Workshop in conjunction with JCWE.Springer-Verlag, Berlin/Heidelberg, 425-430.

[24] Leal, F., Malheiro, B., \& Burguillo, J. C. (2016). Recommendation of Tourism Resources Supported by Crowdsourcing. International Conference on Information and Communication Technologies in Tourism.

[25] Leimeister, J., Huber, M., Bretschneider, U., \& Krcmar, H. (2009). Leveraging crowdsourcing -activation-supporting components for IT-based idea competitions. J. ournal of Management Information Systems, 26 (1), 197-224.

[26] Maione, I. (2013). Paid crowdsourcing: increased know-how is needed. http://www.clickworker.com/en/presseservice.

[27] Marjanovic, S., Fry, C., \& Chataway, J. (2012). Crowdsourcing based business models: In search of evidence for innovation. Science and Public Policy, 1-15.

[28] Mazzola, D., \& Distefano, A. (2010). Crowdsourcing and the participation process for problem solving: the case of BP. VII Conference of Italian Chapter of AIS. Information technology and Innovation trend in Organization.

[29] Oliveira et al. (2010). Definition of a crowdsourcing Innovation Service for the European SMEs. Current Trend in web Engineering - Springer, Berlin/Heidelberg, 412-416.

[30] Poetz, M. K., \& Schreier, M. (2009). The value of crowdsourcing; Can Users Really Compete with Professionals in Generating New Product Ideas? Journal of Product Innovation Management.

[31] Sansom, C. (2011). The power of many', news feature. Nature Biotechnology, 29, 201-203. 
[32] Saxton et al. (2013). Rules of Crowdsourcing: Models, Issues, and Systems of Control. Information Systems Management, 30 (1).

[33] Schenk, E., \& Guittard, C. (2009). Crowdsourcing: What can be Outsourced to the Crowd, and Why? National Institute of Applied Science.

[34] Shao, B., Shi, L., Xu, B., \& Liu, L. (2012). Factors affecting participation of solvers in crowdsourcing: an empirical study from China. Electron Markets, 22, 73-82.

[35] Sigala, M. (2015). Gamification for Crowdsourcing Marketing Practices: Applications and Benefits in Tourism. In Advances in Crowdsourcing. Springer International Publishing., 129145.

[36] Tiwari, S., \& Kaushik, S. (2014). Information Enrichment for Tourist Spot Recommender System Using Location Aware Crowdsourcing. 15th International Conference on Mobile Data Management, 11-14.

[37] Tiwari, S., \& Kaushik, S. (2015). Crowdsourcing Based Fuzzy Information Enrichment of Toursim Spot Recommender Systems. Computational Science and Its Applications/Springer International Publishing, 559-574.

[38] Vohnout, P., Cerba, O., Kafka, S., Fryml, J., Krivanek, Z., \&
Holy, S. (2014). Smart Tourism Data Approach For connecting Local and global tourist information systems. Africa Conference Proceedings, 1-6.

[39] Vukovic, M., Mariana, L., \& Laredo, J. (2009). People Cloud for the Globally Integrated Enterprise. Service-Oriented Computing (Spinger-Verlag, Berlin/Heidelberg.

[40] Wenger, S. (1998). Communities of practice: learning, meaning and identity. Cambridge.

[41] Whitla, P. (2009). Crowdsourcing and Its Application in Marketing. Crowdsourcing Management Research, 5 (1), 1528.

[42] Yang, J., Adamic, L. A., \& Ackerman, M. S. (2008). Crowdsourcing and knowledge sharing: strategic user behaviour on tasken. Proceedings of the 9th ACM conference on Electronic commerce, 246-255.

[43] Zhao, Y., \& Zhu, Q. (2014). Evaluation on crowdsourcing research: Current status and future direction. Springer Science+Business Media, LLC 2012.

[44] Zhuang, Y., Zhunge, F., Chiu, D. K., Ju, C., \& Jiang, B. (2014). A Personalized Travel System Based on Crowdsourcing Model. In Advanced Data Mining and Applications. Springer International Publishing, 163-174. 